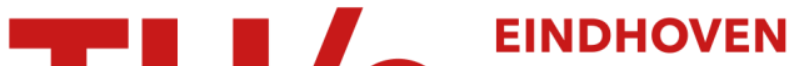 UNIVERSITY OF TECHNOLOGY
}

\section{Optimizing electricity consumption of buildings in a microgrid through demand response}

\section{Citation for published version (APA):}

Morales González, R., Shariat Torbaghan, S., Gibescu, M., Cobben, J. F. G., Bongaerts, M. A., de Nes-Koedam, M., \& Vermeiden, W. (2017). Optimizing electricity consumption of buildings in a microgrid through demand response. In 2017 IEEE Manchester PowerTech, Powertech 2017 (pp. 1-6). [7980983] Institute of Electrical and Electronics Engineers. https://doi.org/10.1109/PTC.2017.7980983

DOI:

10.1109/PTC.2017.7980983

Document status and date:

Published: 13/07/2017

\section{Document Version:}

Accepted manuscript including changes made at the peer-review stage

\section{Please check the document version of this publication:}

- A submitted manuscript is the version of the article upon submission and before peer-review. There can be important differences between the submitted version and the official published version of record. People interested in the research are advised to contact the author for the final version of the publication, or visit the $\mathrm{DOI}$ to the publisher's website.

- The final author version and the galley proof are versions of the publication after peer review.

- The final published version features the final layout of the paper including the volume, issue and page numbers.

Link to publication

\section{General rights}

Copyright and moral rights for the publications made accessible in the public portal are retained by the authors and/or other copyright owners and it is a condition of accessing publications that users recognise and abide by the legal requirements associated with these rights.

- Users may download and print one copy of any publication from the public portal for the purpose of private study or research.

- You may not further distribute the material or use it for any profit-making activity or commercial gain

- You may freely distribute the URL identifying the publication in the public portal.

If the publication is distributed under the terms of Article $25 \mathrm{fa}$ of the Dutch Copyright Act, indicated by the "Taverne" license above, please follow below link for the End User Agreement:

www.tue.nl/taverne

Take down policy

If you believe that this document breaches copyright please contact us at:

openaccess@tue.nl

providing details and we will investigate your claim. 


\section{Optimizing Electricity Consumption of Buildings in a Microgrid through Demand Response}

\author{
R. Morales González, S. Shariat Torbaghan*, \\ M.Gibescu, and J.F.G. Cobben \\ Electrical Energy Systems Group \\ Eindhoven University of Technology \\ Eindhoven, the Netherlands \\ r.m.d.g.morales.gonzalez@tue.nl
}

\author{
M.Bongaerts, M. de Nes-Koedam, \\ and W. Vermeiden \\ Alliander N.V. \\ Arnhem, the Netherlands
}

\begin{abstract}
This paper optimizes the thermodynamic behavior of buildings through demand response (DR) by operating their mechanical heating/cooling systems at $50 \%$ or $100 \%$ output capacity on a 15-minute basis. The optimization's objective is either minimizing cost or net electricity consumption, considering hourly prices and renewable energy resource availability in the local microgrid. The proposed DR framework combines thermodynamic models with an automated, genetic-algorithm based optimization, resulting in demonstrable benefits in terms of cost and energy efficiency for the end-users. The optimal DR schedule with multiple heating/cooling output capacity is compared against an unoptimized, business-as-usual scenario and against a DR schedule which allows only a binary operation. Results show that flexibility can be harnessed from the buildings' thermal mass, and that a finer temporal granularity not only improves the cost- and energy performance of the system, but also the utilization of renewable energy sources in the microgrid.
\end{abstract}

Index Terms-Demand response, genetic algorithm, local RES integration, physical system modeling, smart microgrids.

\section{INTRODUCTION}

Large-scale integration of distributed generation from renewable energy sources (DG-RES) into electricity networks has its pitfalls in preserving reliability and economic feasibility. These pitfalls mainly stem from the loss of flexibility in the generation side of the power system value chain, brought about by the stochastic nature of wind and solar energy resources [1]-[3]. Enabling flexibility from other sources within the power system to compensate for the flexibility lost on the generation side is one of the goals of the so-called smart grids concept [4]. This flexibility entails the shifting of consumption and/or generation with respect to time through, e.g.: enhanced distribution system monitoring and control functionalities, the use of (electrical and/or thermal) storage, the design of new electricity markets, and an increased demand-side flexibility through demand response (DR) programs [4]-[6]. For the purposes of this work, we define DR as "actions voluntarily taken by consumers to change their energy usage — either in

This work was supported by Alliander N.V., and partly by the Intelligent Networks Innovation Program (Innovatieprogramma Intelligente Netten) of the Netherlands Enterprise Agency (Rijksdienst voor Ondernemend Nederland) [project no. IPIN2011.6].

*S. Shariat Torbaghan is now with VITO N.V, Genk, Belgium. terms of quantity or timing - in response to an external control signal" [7], such as price or a command from the system operator. Furthermore, we define load flexibility as "the ability of loads to be shifted in time by automated DR actions" [7].

In this work, we focus on using DR to harness the flexibility of end-user thermostatically-controlled loads (e.g., heating, ventilation and air conditioning systems, refrigerators and water heaters) in response to price signals, while simultaneously considering local DG-RES availability. Our main contributions are the iterative combination of thermodynamic models of buildings with an optimization algorithm into a single DR framework to show 1) how flexibility can be harnessed from the buildings' thermal mass, and 2) what the resulting benefits are in terms of cost and energy efficiency. We test our DR framework with a case study of a microgrid consisting of a refrigerated warehouse and an office building, located in a business park with local PV generation.

This paper is an extension of our previous work [7], with the following improvements:

- The ability to operate the mechanical heating or cooling system of a building at $50 \%$ or $100 \%$ capacity. Previous work included only a binary operation of the heating/cooling system.

- A finer temporal granularity, going from an hourly- to a 15-minute resolution in order to investigate the possibility of smoother indoor temperature profiles and better energy performance, and to be consistent with the time resolution of most balancing markets.

The rest of the paper is organized as follows: Section II describes the mathematical models, and Section III describes the case study used for this work. In Sections IV and V, results are presented and discussed. Finally, conclusions and directions for future work are stated in Section VI.

\section{Methodology}

This section describes the mathematical models and algorithms that make up the physical models, in combination with our optimization-based DR framework. 


\section{A. Thermodynamic modeling}

The thermodynamics of the end-users' buildings can be described by a first-order dynamic system, per works such as [8]-[11]. This simplified representation of end-user premises allows us to 1) capture first-order transients without having to perform a heavily-detailed building simulation, and 2) facilitate the real-time implementation of the optimization framework we use in our DR program. The system of equations describing the thermodynamic behavior of the buildings is given in (1):

$$
\begin{aligned}
\left(m c_{p}\right)_{i c} d T_{i c}(t) / d t & =-\left(T_{i c}-T_{i n}\right) / R_{\text {conv }} \\
\left(m c_{p}\right)_{i n} \frac{d T_{i n}(t)}{d t} & =\frac{T_{i c}-T_{i n}}{R_{\text {conv }}}-\frac{T_{\text {in }}-T_{\text {sup }}}{R_{\text {conv }}} \\
& -\sum_{n=1}^{N} \frac{T_{i n}-T_{e, n}}{R_{e, n, 1}+R_{e, n, 2}} \\
\left(m c_{p}\right)_{e, n} \frac{d T_{e, n}(t)}{d t} & =\frac{T_{i n}-T_{e, n}}{R_{e, n, 1}+R_{e, n, 2}} \\
& -\frac{T_{e, n}-T_{a m b}}{R_{e, n, 3}+R_{e, n, 4}} \quad \forall n \in[1, N] \\
0 & =\left(T_{\text {in }}-T_{\text {sup }}\right) / R_{\text {conv }}+\dot{Q}_{\text {sup }}
\end{aligned}
$$

where $\left(m c_{p}\right)_{x}$ denotes heat capacity in $\mathrm{J} / \mathrm{K} ; d T_{x}(t) / d t$, is the rate of change temperature with respect to time in $\mathrm{K} / \mathrm{s}$; and $R_{x}$ denotes thermal resistance in $\mathrm{K} / \mathrm{W}$. The subscript $x$ is a stand-in for the subscripts $i c$, in and $e, n$, which denote the building's interior contents, indoor air, and $n$ number of building envelope elements out of a total $N$ (e.g., roof, walls, and windows), respectively. $R_{\text {conv }}$ is the thermal resistance due to convective heat transfer in $\mathrm{K} / \mathrm{W}, T_{a m b}$ is the ambient temperature as a function of time in $\mathrm{K}, \dot{Q}_{\text {sup }}$ is the heat supplied or extracted by the mechanical heating or cooling system in watts, and $T_{\text {sup }}$ is the supply temperature of the mechanical heating/cooling system in K.

Mechanical heat supplied or extracted is given by (2):

$$
\dot{Q}_{\text {sup }}(t)=\left(\dot{m} c_{p}\right)_{a i r}\left(T_{\text {sup }}-T_{\text {in }}(t)\right)
$$

where $\dot{m}_{a i r}$ is the mass flow and $c_{p, a i r}$ is the specific heat capacity at $0^{\circ} \mathrm{C}$ of the conditioned air. Mechanical heat supplied or extracted is related to electrical power consumption, denoted by $\dot{W}_{e l}$, through the so-called coefficient of performance (COP), defined by (3):

$$
\begin{aligned}
C O P & =\dot{Q}_{\text {sup }} / \dot{W}_{\text {el }} \\
C O P & =b_{0}+b_{1} T_{a m b}+b_{2} T_{\text {sup }} \\
& +b_{3} T_{a m b}^{2}+b_{4} T_{\text {sup }}^{2}+b_{5} T_{a m b} T_{\text {sup }}
\end{aligned}
$$

where (3a) is the classical definition, and (3b) is an approximation of the COP as a quadratic function of the conditioned air supply and ambient temperatures.

\section{B. Optimization problem formulation}

Let us consider that the ON/OFF signal of the heating/ cooling system of end-user $i$ at time $t$ is defined by variable $\beta(i, t)$, which is integer-constrained to the number of heating/cooling output stages. The net energy imported from the grid of all $I$ end-users connected to the business park microgrid, $E_{\text {net }}(t)$, after combining the predicted contribution of local DG-RES in the microgrid $E_{R E S}(t)$ and the electricity consumption of the mechanical heating or cooling system of end-user $i$ at time $t, E(i, t)=\int_{t-1}^{t} \dot{W}_{e l}(i, t) d t$, is expressed by (4).

$$
E_{n e t}(t)=\sum_{i=1}^{I} \beta(i, t) E(i, t)-E_{R E S}(t)
$$

The optimization problem (5a) signifies choosing the switching schedules $(\beta(i, t))$ and the PV production schedule $E_{R E S}(t)$ over the whole time horizon, with the objective of minimizing energy consumption (6) or energy cost (7). The building temperatures $\left(T_{i n}(i, t)\right)$ must not exceed the critical values required by the end-users (5b). DG-RES exports from the microgrid to the public distribution grid are curtailed under the assumption that there is a restrictive framework and/or no financial incentive present for feeding excess PV production back into the regional distribution network (5c). Finally, physical constraints of local DG-RES production (5d) are considered. The optimization problem takes on the form (5):

$$
\begin{aligned}
\min _{\beta, E_{R E S}} & \Omega=\Phi \\
\text { s.t. } & T_{\min }(i, t) \leq T_{\text {in }}(i, t) \leq T_{\max }(i, t) \quad \forall i, t \\
& E_{\text {net }}(t) \geq 0 \quad \forall t \\
& 0 \leq E_{R E S}(t) \leq E_{R E S}^{\max }(t) \quad \forall t
\end{aligned}
$$

where $\Phi$ is $\Phi_{e}(6)$ in the energy consumption minimization and $\Phi_{c}(7)$ in the energy cost minimization problems:

$$
\begin{gathered}
\Phi=\Phi_{e}=\sum_{t=1}^{T} E_{n e t}(t) \\
\Phi=\Phi_{c}=\sum_{t=1}^{T} \lambda(t) E_{n e t}(t)
\end{gathered}
$$

where $\lambda(t)$ is the predicted price of electricity at time $t$.

The resulting mixed-integer optimization problem is solved using a genetic algorithm (GA).

\section{Interaction between models}

While conventional mechanical heating/cooling system temperature controls have a fixed set-point temperature and fixed temperature trip points, our multiphysics DR framework couples and iteratively intertwines the thermodynamic building models with the GA-based optimization framework to devise optimal on/off strategies for the heaters/chillers in all the buildings in the microgrid, such that the objectives of either minimal cost or maximal energy efficiency are achieved. Note 


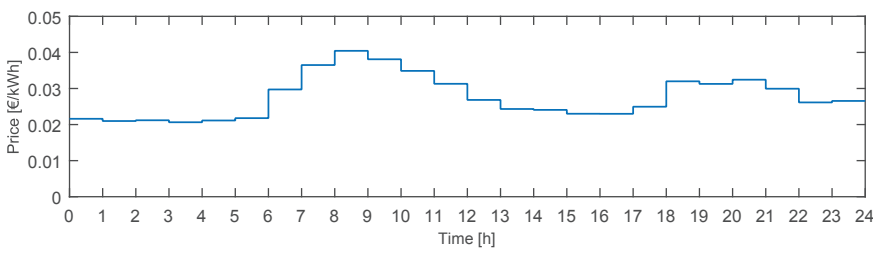

Fig. 1. Dynamic electricity prices for the end-users of the microgrid.

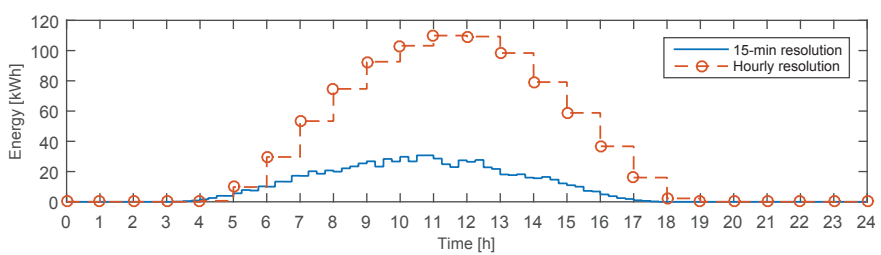

Fig. 2. PV production profiles for an average-temperature day in the Netherlands, (1600 $\mathrm{m}^{2} \mathrm{PV}$ panels and an overall system efficiency of $\left.12 \%\right)$.

that the optimization problem will determine the entire 24hour switching schedule in advance of real-time, assuming perfect knowledge of all influencing factors: short-term PV production, market prices, and outdoor temperatures.

\section{CASE STUDY}

This section describes the simulation experiments and main assumptions used in this work. Our DR framework aims to optimize the mechanical heating or cooling schedules of two customers in a grid-connected microgrid - a refrigerated warehouse used as a bulk storage cooling facility and a medium office building - over a day-ahead time horizon, for an average-temperature day in the Netherlands.

We focus on the flexible heating and cooling energy consumption required to maintain indoor/product temperatures within the specified comfort limits, which are within the intervals [19,21] and [1,3] $\pm 0.3{ }^{\circ} \mathrm{C}$ for the office building and the refrigerated warehouse, respectively. We neglect in our calculations the base electricity load and any loads triggered by human interaction. Heating or cooling loads required to balance ventilation and internal heat gains/losses from lighting, people, equipment, and new incoming products (in the case of the refrigerated warehouse), are all considered part of the baseload because of their inflexible nature (i.e., that they are not shiftable in time).

Expected day-ahead electricity prices $^{1}$ and PV generation values used in the simulations are shown in Fig. 1 and Fig. 2.

Two optimization objectives are considered: 1) energy minimization and 2) cost minimization.

The optimization results for hourly- and 15-minute resolution are compared against a Business-As-Usual (BAU) scenario, where temperature control in the buildings is driven by a continuously-operating floating thermostat. Such a thermostat has variable setpoints and deadbands that change according to heuristic decision trees based on a three-tier price signal classification at the current time step (low-medium-high), in order to use the mechanical heating/cooling as much as

\footnotetext{
${ }^{1}$ Based on data from https://transparency.entsoe.eu/
}

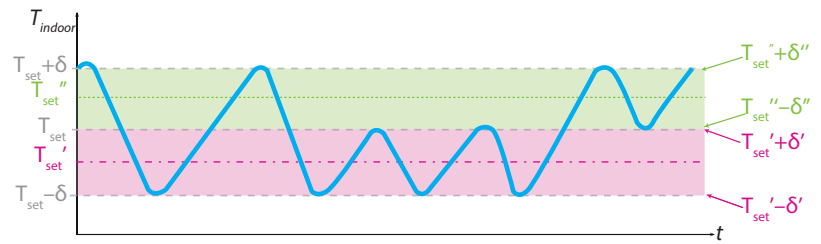

Fig. 3. Schematic depiction of a floating thermostat controller.

possible when prices are lowest (i.e., at full capacity) and use it as least as possible (i.e., none at all, or at half-capacity) when they are the highest. Fig. 3 schematically depicts a floating thermostat controller. In the case of a mechanical cooling system, for example: $T_{\text {set }}^{\prime}, T_{\text {set }}$, and $T_{\text {set }}^{\prime \prime}$ in Fig. 3 represent the temperature setpoints when prices are low, average and high, respectively, while $2 \delta^{\prime}, 2 \delta$, and $2 \delta^{\prime \prime}$ are the thermostat's respective deadbands. All results will also be compared to those of a binary operation mode from our previous work [7].

The design variables of the optimization problem are the hourly switching schedules of the mechanical heating or cooling system for all buildings, $\beta(i, t)$, and the hourly DGRES production schedules, $E_{R E S}(t)$. To enable operation at $50 \%$ and $100 \%$ rated capacity, we assume that, for every building, there are two heat pumps in operation, each rated at $50 \%$ of the total heating/cooling capacity of the mechanical system. Therefore, $\beta$ is integer-constrained in the interval [0,2], while $E_{R E S}$ is a continuous non-negative variable. For the 24-hour time horizon of the case study, and in the hourly resolution mode, $\beta$ has a length of 48 (24 variables per building) and the microgrid-aggregated $E_{R E S}$ has a length of 24 , resulting in a phenotype of 72 elements for the GA. In the 15-minute resolution mode, $\beta$ has a length of 192 (96 variables per building) and $E_{R E S}$ has a length of 96 , resulting in a phenotype of 288 elements. This increases the complexity of the GA used to solve our mixed-integer problem.

\section{RESUlts}

This section presents the simulation results for the BAU scenario, plus the energy amount and energy cost optimizations in the hourly- and 15-minute resolution modes. Results for each scenario are shown graphically in Figs. 4-8, and are summarized and compared against each other in Table I.

\section{A. BAU scenario}

Simulation results for the BAU scenario are shown in Fig. 4, which contains three subplots. The topmost subplot (a) shows building and ambient temperatures with respect to time. The middle subplot (b) shows the number of compressors that are on for each building at every time step. Finally, the bottom subplot (c) shows the electrical energy consumption and generation with respect to time, with positive values denoting consumption and negative values denoting generation.

It is possible to see from Fig. 4(b) that the heating/cooling systems of both the office (red dashed line) and refrigerated warehouse (solid blue line) are running at full power $(\beta=$ 2 ) when electricity prices are the lowest (hours 0-6 and 1318), while the heating/cooling systems are running at $50 \%$ 
TABLE I

OPTIMIZATION RESULTS FOR BINARY- AND MULTIPLE-OUTPUT MODES, AND FOR THE BAU SCENARIO.

\begin{tabular}{|c|c|c|c|c|c|c|c|c|}
\hline \multirow[b]{2}{*}{ Scenario } & \multicolumn{4}{|c|}{ Energy $[\mathrm{kWh}]$} & \multirow{2}{*}{$\begin{array}{c}{[€]} \\
\text { Total cost }\end{array}$} & \multicolumn{3}{|c|}{$[\%]$} \\
\hline & Warehouse & Office & PV & Net load & & Cost savings & Energy savings & PV utilization \\
\hline \multicolumn{9}{|c|}{ Multiple output heating/cooling capacity } \\
\hline BAU & 1016.2 & 258.6 & 370.2 & 904.6 & 21.4 & - & - & 42.6 \\
\hline Energy optimization, 60' & 866.3 & 206.3 & 383.0 & 689.6 & 18.81 & 12.2 & 23.8 & 44.0 \\
\hline Cost optimization, $60^{\prime}$ & 876.1 & 207.8 & 375.9 & 708.0 & 18.32 & 14.5 & 21.7 & 43.2 \\
\hline Energy optimization, 15' & 896.8 & 197.9 & 500.4 & 594.3 & 16.11 & 24.8 & 34.3 & 57.5 \\
\hline Cost optimization, 15 & 899.6 & 205.1 & 477.8 & 626.9 & 15.67 & 26.8 & 30.7 & 54.9 \\
\hline \multicolumn{9}{|c|}{ Binary heating/cooling mode (from [7]) } \\
\hline Energy optimization, 60' & 1045.4 & 248.40 & 473.03 & 820.79 & 21.08 & 1.6 & 9.3 & 54.4 \\
\hline Cost optimization, 60’ & 987.59 & 230.89 & 377.47 & 841.01 & 20.10 & 6.2 & 7.0 & 43.4 \\
\hline
\end{tabular}
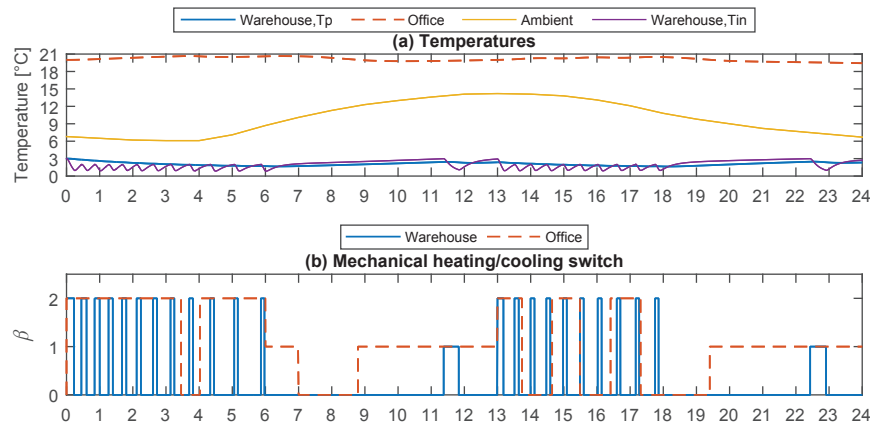

(c) Electrical Energy Consumption and Generation

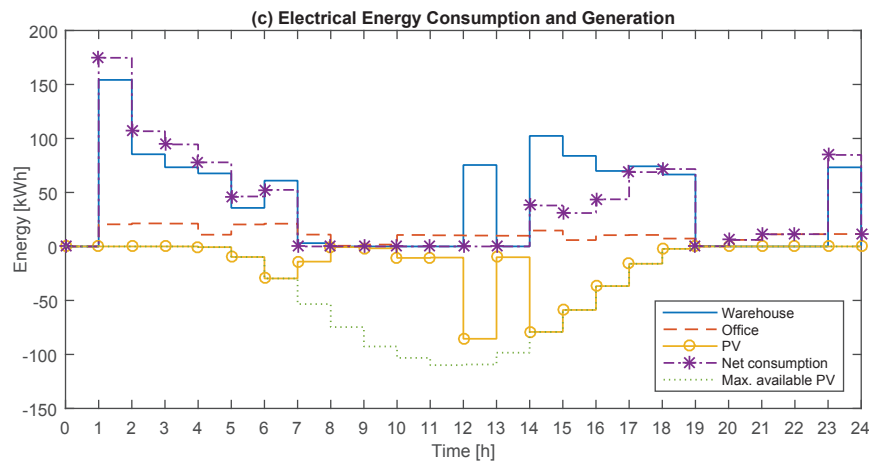

Fig. 4. Results for the BAU scenario

( $\beta=1)$ or shut off entirely $(\beta=0)$ when electricity prices are the highest. However, since the floating thermostat of the BAU scenario does not take DG-RES availability into account, PV resources are under-utilized, especially at times where PV production is the highest (see Fig. 4(c) and Table I).

\section{B. Optimization results}

Optimization results using an hourly resolution are shown in Fig. 5 for the energy minimization objective, and Fig. 6 for the cost minimization objective. Optimization results using a 15-minute resolution are similarly shown in Fig. 7 and Fig. 8 for energy and cost, respectively. The subplots and legends for all optimization results are analogous to those of Fig. 4.

1) Hourly resolution: The energy minimization objective is apparent in Fig. 5(b), in that, with the exception of the refrigerated warehouse at time 0 , the heating/cooling systems
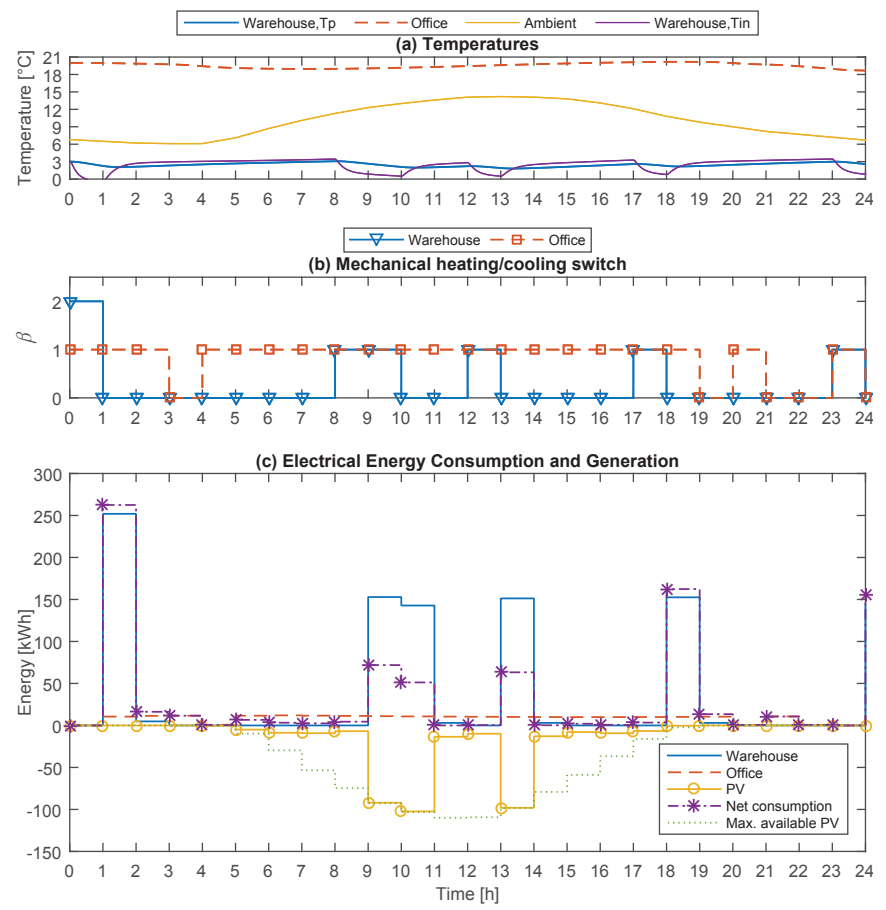

Fig. 5. Results for energy minimization, hourly resolution

of both buildings are either operating at 50\% capacity or not at all. The ability to reduce the heating/cooling load without infringing upon the thermal comfort boundaries is due to the buildings' thermal mass; i.e., the summation of the heat capacities of the different building elements: term $\left(m c_{p}\right)_{x}$ in (1). Even though the PV utilization rate does not improve much with respect to the BAU scenario, energy performance improves by almost $24 \%$ and cost reduces by $12 \%$ in the energy minimization scenario.

From Table I, although net energy consumption is slightly higher in the cost optimization scenario, cost performance slightly improves, signifying a reduction of almost $15 \%$ with respect to the BAU scenario. While in the BAU scenario, electricity consumption focuses around the time prices are the lowest, the energy optimization results in Fig. 6(c) show that consumption is more evenly distributed throughout the day 


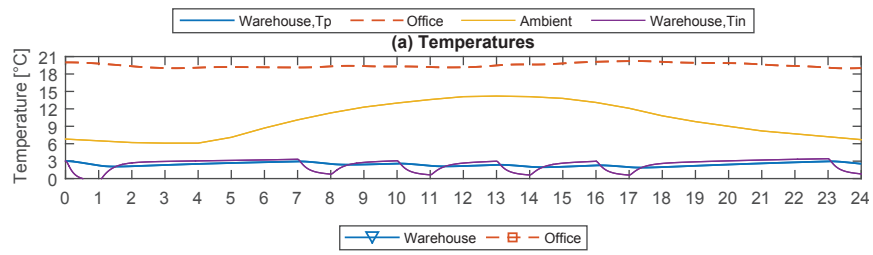

(b) Mechanical heating/cooling switch

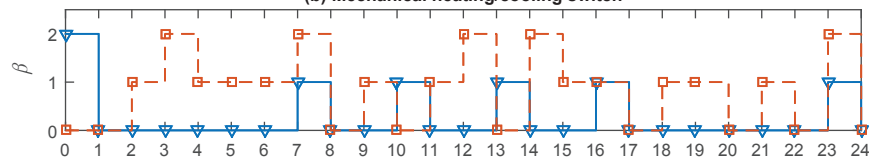

(c) Electrical Energy Consumption and Generation

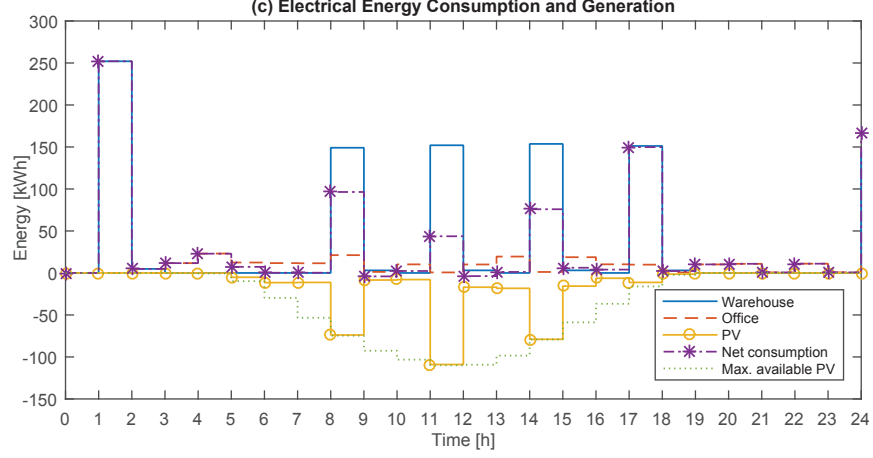

Fig. 6. Results for cost minimization, hourly resolution

to not only take advantage of favorable prices, but also the periods of highest $\mathrm{PV}$ production.

2) 15-minute resolution: The higher number of switching operations of the heating/cooling systems in the 15-minute resolution allows for much improved utilization rates of PV in both the energy- and cost minimization objectives: 57\% and $55 \%$ for the energy- and cost optimization scenarios, respectively. Results show that the optimizations using a 15minute time resolution outperform all other scenarios significantly with regard to PV utilization, with the exception of the energy optimization using binary mode, which produced a similar PV utilization rate. Total cost decreased by almost $25 \%$ for the energy minimization scenario and $27 \%$ for the cost minimization scenario with respect to BAU scenario. This represents an improvement of performance of $14 \%$ in both cases when compared to the simulations using an hourly resolution. Similarly, energy consumption was decreased by $34 \%$ and $30 \%$ in the energy- and cost minimization scenarios using a 15-minute resolution when compared to the BAU case, signifying a $13 \%$ and $11 \%$ improvement with respect to simulations using an hourly resolution.

However, the initial hypothesis that a finer temporal granularity would allow for a greater temperature stability cannot be confirmed for the case of the refrigerated warehouse. Table II shows the standard deviation of the temperatures for every building and every optimization scenario. It can be seen that $\sigma_{o}$ decreased for the 15-minute resolution experiments for the office building, but the opposite occurred for $\sigma_{w}$ in the case of the refrigerated warehouse. This is because the times at which the cooling system is on in both scenarios cluster much more around the times when PV production is available, making
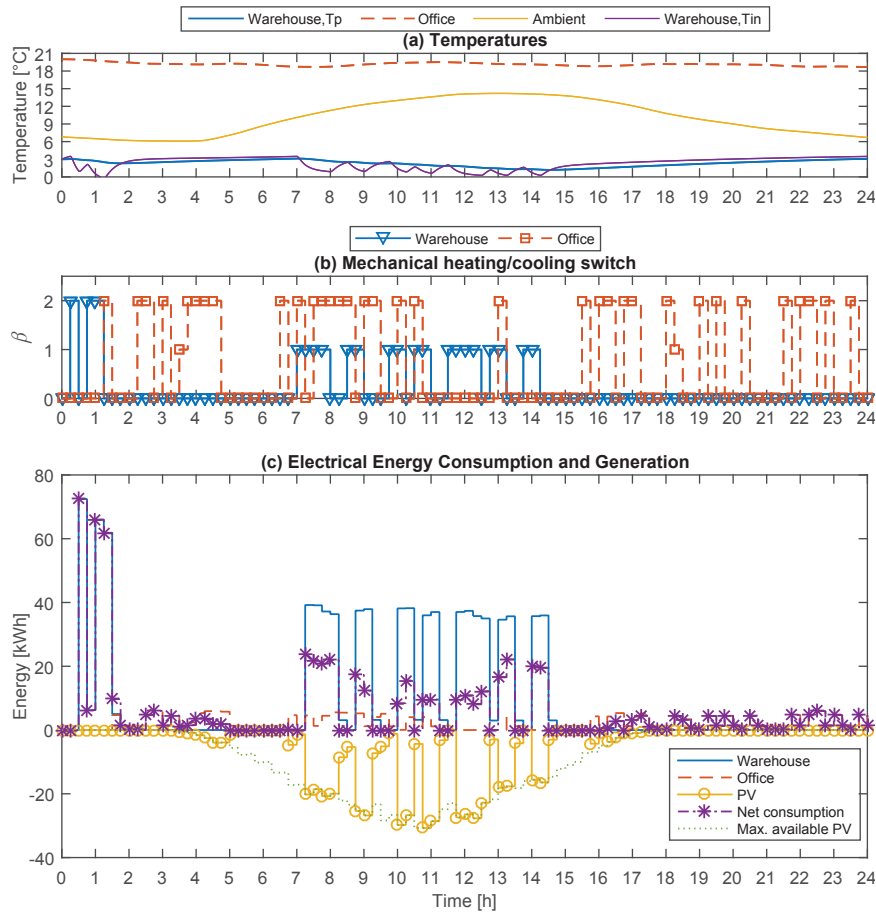

Fig. 7. Results for energy minimization, 15 ' resolution
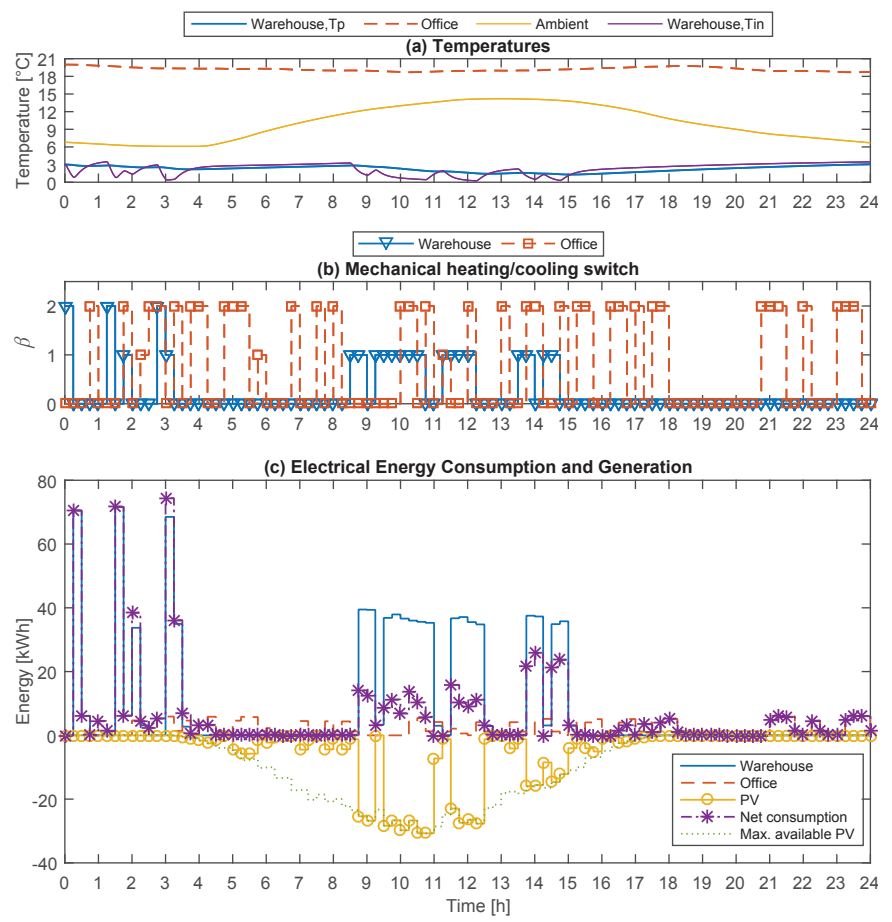

Fig. 8. Results for cost minimization, 15' resolution

the temperatures towards the end of the day (from hour 15 onwards) rise considerably, albeit within the allowable limits (see Figs. 7 and 8).

3) Comparison to binary mode: From Table I, it is possible to see that the multiple output heating/cooling capacity optimization is clearly more energy- and cost efficient than the binary mode, simply because of the ability to modulate the 
TABLE II

STANDARD DEVIATION, $\sigma$, OF TEMPERATURE VALUES

\begin{tabular}{lccccc}
\cline { 2 - 3 } & \multicolumn{2}{c}{ Warehouse, $\sigma_{w}$} & & \multicolumn{2}{c}{ Office, $\sigma_{o}$} \\
\cline { 2 - 3 } \cline { 5 - 6 } \cline { 5 - 6 } & Hourly & 15 -minute & & Hourly & 15 -minute \\
\hline Energy optimization & 0.36 & 0.57 & & 0.42 & 0.30 \\
Cost optimization & 0.32 & 0.51 & & 0.38 & 0.33 \\
\hline
\end{tabular}

power output of the heating/cooling systems of the buildings with an additional step. This control mechanism is achievable, from a practical standpoint, in systems with multiple heat pump sets or modulating compressor technologies (such as inverter-based heat pumps or multi-stage compressors).

However, it is important to note that the GA-based controller with binary heating/cooling still outperforms the floating thermostat controller of the BAU scenario, despite the fact that the BAU thermostat controller has the multiple output capability. This is due to the fact that the floating thermostat bases its control decisions per time step, whereas the GA-based controller is able to look ahead throughout the whole 24-hour time horizon to create the optimal switching schedules for the heating/cooling systems of the buildings.

\section{Discussion}

The results presented in the previous section show the potential of implementing price-responsive DR programs in microgrids to harness flexibility from buildings' thermal mass. The benefits of harnessing this flexibility are clear and attractive, in terms of better PV utilization rates and reductions in the amount and overall cost of heating/cooling electricity demand for the flexible end-users connected to the microgrid. However, additional work has to be done in order to make the implementation of the proposed DR framework practical, and surmount some of the simplifying assumptions made when computing the optimal schedules.

For example, it is important to note that, given that the optimization problems that make up our DR framework are non-linear and mixed-integer, the heuristic methods used to solve them require multiple successive simulation runs from which the best local optima can be selected. By increasing the number of design variables when moving from 1 hour to a finer temporal granularity of 15 minutes, the solving time increases by approximately a factor of 4 (e.g., from under $2 \mathrm{~h}$ to over $7 \mathrm{~h}$ using 28 parallel processing pools in MATLAB), which negatively affects the computational feasibility of the problem. That means that, depending on the number of customers in the microgrid, the computation time could take longer than the 24hour window in which the scheduling has to be made. Such a situation would render the use of the 15-minute resolution infeasible for the microgrid aggregating entity. The increase in simulation time could be offset by increasing computational resources in the parallelized search for feasible solutions and using more powerful/faster optimization tools, although this could represent additional investment costs for the entity in charge of DR in the microgrid.

\section{CONCLUSIONS}

This paper extended previous work done in the area of modeling and optimizing the thermodynamic behavior of buildings through DR, by adding the ability to operate the mechanical heating/cooling systems at $50 \%$ or $100 \%$ capacity, and a finer temporal resolution. In summary, the results presented show that:

- Flexibility can be harnessed from the buildings' thermal mass, resulting in significant benefits in terms of cost and energy efficiency for the end-user.

- Operating heating/cooling systems with multiple-output capacity shows a significant increase in both energy and cost savings with respect to the binary operation mode and the BAU scenario.

- Using a finer temporal granularity further improves PV utilization rates, as well as energy and cost performance, though the increased number of design variables of the optimization problem entails an increased computational complexity.

- The proposed GA-based temperature controller outperforms the decision-tree-based thermostat from the BAU scenario, even when the GA controller is operating in combination with a binary output mode.

Further work for future publications includes adding network constraints to the industrial microgrid model, and adding thermal storage capabilities.

\section{REFERENCES}

[1] European Commission, "Energy 2020: A strategy for competitive, sustainable, and secure energy," EU, Luxembourg, Tech. Rep., 2011.

[2] _ " "2011 Technology Map of the European Strategic Energy Technology Plan,” Joint Research Centre-Institute for Energy and Transport, Luxembourg, Tech. Rep., 2011.

[3] C. Hewicker, M. Hogan, and A. Mogren, "Power Perspectives 2030: On the road to a decarbonised power sector," Roadmap 2050, Den Haag, Tech. Rep., 2012.

[4] A. Mansoor, C. Gellings, and R. Schoff, "Power System Flexibility," Smart Grid, aug 2013. [Online]. Available: http://smartgrid.ieee.org/ august-2013/952-power-system-flexibility

[5] European Commission, EUR 22040 European Technology Platform SmartGrids. Luxembourg: Office for Official Publications of the European Communities, 2006.

[6] EU Commission Task Force for Smart Grids, "Expert Group 1: Functionalities of smart grids and smart meters," European Commission, Brussels, Tech. Rep., dec 2010.

[7] R. Morales González, S. Shariat Torbaghan, M. Gibescu, and S. Cobben, "Harnessing the Flexibility of Thermostatic Loads in Microgrids with Solar Power Generation,” Energies, vol. 9, no. 7, p. 547, jul 2016. [Online]. Available: http://www.mdpi.com/1996-1073/9/7/547/htm

[8] E. L. Zaparoli and M. de Lemos, "Simulation of Transient Response of Domestic Refrigeration Systems," in Int. Refrig. Air Cond. Conf. West Lafayette: Purdue University, 1996, pp. 495-500.

[9] K. Kalsi, F. Chassin, and D. Chassin, "Aggregated modeling of thermostatic loads in demand response: A systems and control perspective," in Decis. Control Eur. Control Conf. (CDC-ECC), 2011 50th IEEE Conf. Orlando: IEEE, dec 2011, pp. 15-20.

[10] L. Hurtado, E. Mocanu, P. Nguyen, and W. Kling, "Comfort-constrained demand flexibility management for building aggregations using a decentralized approach," in SmartGreens 2015 - 4th Int. Conf. Smart Cities Green ICT Syst., Lisbon, may 2015, pp. 157-166.

[11] M. B. Wilson, R. Luck, and P. J. Mago, "A First-Order Study of Reduced Energy Consumption via Increased Thermal Capacitance with Thermal Storage Management in a Micro-Building," Energies, vol. 8, pp. 12266 12282,2015 